PLANNING FOR DATA COMMUNICATIONS 
By the same authors

A HANDBOOK OF SYSTEMS ANALYSIS 


\section{PLANNING FOR DATA COMMUNICATIONS}

\section{JOHN E. BINGHAM}

A.C.I.S., A.M.B.I.M., M.B.C.S., M.D.P.M.A.

\section{GARTH W. P. DAVIES}

M.A. (Cantab.), M.I.Inf.Sc. 
() John E. Bingham and Garth W. P. Davies 1977

All rights reserved. No part of this publication may be reproduced or transmitted, in any form or by any means, without permission

First edition 1977

Reprinted 1983

Published by

THE MACMILLAN PRESS LTD

London and Basingstoke

Companies and representatives

throughout the world

ISBN 978-0-333-21276-9 ISBN 978-1-349-86143-9 (eBook)

DOI 10.1007/978-1-349-86143-9

Type set in IBM Press Roman

by Preface Ltd, Salisbury, Wilts

The paperback edition of this book is sold subject to the condition that it shall not, by way of trade or otherwise, be lent, resold, hired out, or otherwise circulated without the publisher's prior consent in any form of binding or cover other than that in which it is published and without a similar condition including this condition being imposed on the subsequent purchaser. 


\section{Contents}

Foreword vii

$\begin{array}{ll}\text { Preface } & \text { ix }\end{array}$

Acknowledgements $\quad$ xi

Part I Systems Strategy for Data Communications 1

1 Phased Development 3

2 Off-line Data Transmission $\quad 6$

3 Remote Batch 12

4 On-line Data Collection without Updating 16

5 Enquiry-Response Systems 22

6 Real-time Systems $\quad 30$

Part II Key Factors in Using Data Communications 41

7 Determining User Needs 43

8 Pilot Systems $\quad 56$

9 Elements of a Network 61

10 Configuring the Network 75

11 Facilities for Data Transmission 85

12 Data Communications Software 101

13 Command Language 118

14 Choice of Terminal 125

15 Mixed Hardware 139 
17 User Training

\section{Part III Pitfalls to Avoid}

$\begin{array}{lll}18 & \text { Overcomplication } & 167\end{array}$

19 Too Much Dependence on Technology 171

20 Lack of User Orientation 173

$\begin{array}{ll}21 & \text { Inadequate Reliability } \\ \end{array}$

$\begin{array}{llr}22 & \text { Insufficient Statistics } & 179\end{array}$

23 Poor Strategy for Implementation $\quad 182$

$\begin{array}{ll}\text { Postscript } & 185\end{array}$

$\begin{array}{ll}\text { Bibliography } & 187\end{array}$

$\begin{array}{ll}\text { Glossary of Terms } & 190\end{array}$

$\begin{array}{ll}\text { Index } & 215\end{array}$ 


\section{Foreword}

The growth and well-being of modern society is increasingly dependent on intercommunication and co-operation between individuals, organisations and nations. The telephone heralded a new era in human interaction by dramatically diminishing the constraints of time and distance, but a far greater impact is being made by the contemporary evolution of data communications. This is bringing a new dimension to human affairs by making possible rapid and convenient exchange of all kinds of information: weather forecasts, laboratory research data and market analyses for multinational organisations are just some examples of the many activities which now take place far more effectively than ever before. In a sense we are witnessing a 'silent revolution' because there seems little clamour for recognition by the professionals bringing it about - they are far too busy planning the next advance.

It is a privilege for me to be associated with some of the efforts and people engaged in this process of rapid but quiet change, who are typified by the authors of this book. They are, indeed, professionals who are bringing the application of the concept of data communications to practical reality for people in many kinds of work, by helping organisations to exchange data, to communicate with each other and to interact on a day-to-day basis. I believe that in this book the authors help us move forward firmly in the right direction, by showing how a careful, logical, step-by-step approach can be followed successfully by any organisation in planning its use of data communications.

It is noteworthy that the authors advocate simplicity of approach, caution and repeated consultation at all stages of design with the ultimate users of the information systems to be installed. The reader will not find exotic plans for ambitious systems but rather practical ideas with a high probability of success. It was therefore with pleasure that I accepted the invitation to write the foreword to this book, because it provides practical guidelines to anyone whose interest it is to install effective systems utilising that modern management tool: data communications.

DEREK L. A. BARBER

Director

EUROPEAN INFORMATICS NETWORK 


\section{Preface}

There is a real danger that with increasing technical sophistication the purpose of information systems will be obscured. Every technical advance in the computer field makes it a little more difficult for the manager to maintain a clear view of the goals of the activities for which he is responsible. Yet it is of vital importance that this perspective be maintained and encouraged. Two sad epitaphs mar the pages of time: 'This is old; therefore it is good' and 'This is new; therefore it is better'. Truth to tell, newness is irrelevant unless related to the businessman's over-all objectives. One of the recurring problems of the development of computer technology to date has been the failure to absorb this simple lesson. As a result, progress has all too often been determined by the innovativeness of the technicians rather than the needs of the business. Even more regrettably, the situation tends to worsen rather than improve as the technology becomes more and more complex. It is at precisely this point that the basic needs have to be most closely considered, since the investments have become so large that they can no longer be shrugged off even by the biggest concerns. Moreover, the potential benefits to the concern (if the technology is properly used) have also risen.

In recent years the development of data communications has had a particular impact. The marriage of communications technology to that of computers has given rise to a whole new field of systems opportunities. In an earlier work $\dagger$ the authors identified the main reason for the growth in data communications, namely the fact that although modern computer technology has contributed much to the speed at which processing of data can take place, it does not by itself do much to shorten the time interval between the origin of data and the availability of processed information. Indeed the most prevalent influence of computer technology on this information cycle was probably to lengthen it, since many computer systems necessitated the batching of data and such systems were used to replace transaction-orientated clerical systems. Thus clerical systems that were able as a byproduct to produce information (though too few of them ever did) accurate to the last transaction processed - and were frequently completely up to date on a dayto-day basis - were often replaced by computer systems, which were only up to the date of the last processing run. Since many systems operated on the basis of weekly or even less frequent computer runs and the data processed on these runs were often two or three days old because of the need to translate (key punch) the data into computer format, the actual information available was often more than seven days old. This then was the basic raison d'être that necessitated the marriage of data communications technology to computers if the latter were to realise their full potential. 
This area seems deeply technical and a person becoming involved in data communications is faced with a new world of jargon and equipment. The concepts, however, are simple and easily applicable. The problem is to set sensible guidelines and goals, which will be based on the benefits of data communications technology, at the same time retaining clear sight of the underlying purpose. In short, the goal of the information systems developer is to utilise advanced technology in the way that best serves the end-user (the accountant, the production manager, the personnel department, etc.) and the organisation as a whole.

This can only be achieved by the pursuit of a strategy for systems development. Each technical possibility is then assessed purely in terms of its contribution to the over-all strategy. However sophisticated the long-term systems plans may be, their achievement is based on a systematic build-up of technical capability, rather than a rush to the most advanced possibility, which is too often the temptation when confronted with experts in the field of data communications. This temptation, if not resisted, can frequently lead to expensive failure - failure in the technological aspects and, worse, failure to meet the business objectives.

This book aims at giving guidance to those concerned with the task of information systems development, but who are not data communications specialists. As such, it is meant to be helpful for data-processing managers, systems analysts and executives responsible for systems development in their organisations. The treatment is based on a step-by-step description of the progressive implementation of an over-all strategy, followed by identification of the main factors that determine the success of such a strategy (cost, geographical priorities, etc.). The approach described is applicable to almost any systems programme, regardless of its current state of development or the size of organisation; variations in these factors are taken into account by the extension or elimination of appropriate steps.

The reader is expected to have a moderate knowledge of systems development based on computers, but no detailed knowledge of data communications is assumed. The text does not emphasise either the theory or equipment side of data communications, but concentrates on the application of the technology to ordinary business and administrative situations.

The final part of the book provides an analysis of where systems based on data communications often go wrong. This is drawn from the practical experience of the authors and is meant to provide important reading for anyone concerned with the actual implementation of data communications. 


\section{Acknowledgements}

We should like to thank the Commission of the European Communities, SCANNET, TELENET and TYMSHARE for permission to reproduce the diagrams in chapter 11, and the National Computing Centre for permission to reproduce the search example in chapter 13 . We thank the Editor of L'Informatique Nouvelle, for permission to reproduce material in Part I, which has already appeared in that journal. We should also like to express our thanks to all those friends and colleagues in the data-processing fraternity with whom we have discussed all the topics covered in this book and who have helped us to formulate our own views on the subject.

Our greatest debt is, once again, to our wives for their typing and editing and above all for their patient forbearance during the many hours of work that a book of this nature requires.

J. E. B.

G. W. P. D. 